\title{
Impact of Climate Comfort on Tourism in Putian City and Countermeasures
}

\author{
Zheng Xiao', Huqing Heํ, Gang Li ${ }^{1}$, Decai Tang² \\ ${ }^{1}$ Putian City Xiuyu District Meteorological Bureau, Putian, China \\ ${ }^{2}$ Nanjing University of Information Science and Technology, Nanjing, China \\ Email: 120439967@qq.com
}

How to cite this paper: Xiao, Z., He, H.Q., Li, G. and Tang, D.C. (2018) Impact of Climate Comfort on Tourism in Putian City and Countermeasures. Journal of Geoscience and Environment Protection, 6, 157-169.

https://doi.org/10.4236/gep.2018.69012

Received: August 10, 2018

Accepted: September 17, 2018

Published: September 20, 2018

Copyright $\odot 2018$ by authors and Scientific Research Publishing Inc. This work is licensed under the Creative Commons Attribution International License (CC BY 4.0).

http://creativecommons.org/licenses/by/4.0/

\begin{abstract}
Putian is an emerging tourist city in Fujian Province. It not only has Weizhou Island, the birthplace of the world's Mazu culture, but also the national 4A scenic spot, like Jiuyi Lake, Jiulong Valley, South Shaolin, etc., attracting thousands of tourists every year. This paper uses meteorological data of the Putian Municipal Meteorological Bureau from 1988 to 2017, negative oxygen ion data in the scenic spots of Weizhou Island, Jiuyi Lake and Jiulong Valley from 2014 to 2017 and monthly data of tourists from 2011 to 2017 provided by Putian City Tourism Bureau. Based on the Temperature and Humidity Index, the Wind Cold Index, the Index of Cloth Loading and the Air Comfort Index, this paper uses the analytic hierarchy process (AHP) to construct a new comprehensive climate comfort model. Using the new model, the climate comfort index of Putian is calculated, and the levels and time periods suitable for tourism are divided. The number of tourists in Putian City is increasing year by year and has obvious time distribution characteristics. There are two peak periods in which tourists are concentrated in each year, which are April to May and October to November, belonging to the spring-autumn type. This paper also uses Ordinary Least Square (OLS) regression method to analyze the climate comfort and tourist traffic. The results show that there is a clear correlation between the comfort index and the passenger flow. Accordingly, suggestions for improvement of tourism development in Putian are proposed.
\end{abstract}

\section{Keywords}

Putian, Climate Comfort, Analytic Hierarchy Process, Passenger Flow

\section{Introduction}

Climate comfort indicates the degree to which the human body feels comfortable or uncomfortable under the combined effect of the external meteorological en- 
vironment, which has profound implications for the development of holiday resorts. In recent years, some scholars have carried out urban climate comfort evaluation. For example, Tang Decai [1] [2] firstly used the FAHP model to evaluate Xiamen's tourism climate comfort, and carried out a fuzzy evaluation of Xiamen in terms of climate change impact on tourism. The fuzzy analysis method was also used to analyze the constraints of environmental factors on the development of China's productive forces [3], which has been unanimously recognized in the field. In order to provide climatological basis for the rational planning and development of tourism in Putian, this paper uses the basic climate data of Putian City from 1988 to 2017, meteorological data from three artificial observation stations in Putian, Xianyou and Xiuyu in Putian City from 1988 to 2017 and negative oxygen ion data for three scenic spots in Weizhou Island, Jiuyi Lake and Jiulong Valley from 2014 to 2017, and determines weights by AHP analytic hierarchy process, then assigns graded values for Temperature and Humidity Index, Wind Cold Index, Index of Cloth Loading [4] [5] [6] and Air Comfort Index, constructing a comprehensive climate comfort model for tourism and evaluating the climate comfort of Putian. This paper also uses the OLS method to analyze the correlation between climate comfort index and monthly passenger flow index. Finally, based on the evaluation model, recommendations are made for months with high comfort but low passenger flow to increase passenger flow. The innovation of this paper is that the model adds the Air Comfort Index, which is a well-received influence factor, making the evaluation model more perfect, and uses AHP and OLS regression analysis, highlighting the accuracy and scientificity of this model.

\section{Methodology}

AHP is a systematic and hierarchical analysis method combining qualitative and quantitative. Through the expert scoring, the elements in a certain layer and the importance of a certain level of its higher level are compared in pairs, thereby constructing a judgment matrix with the same order as the number of elements being compared. Let a layer has $n$ factors $X=\left\{x_{1}, x_{2}, \cdots, x_{n}\right\}$, compare their influence on a certain criterion (or target) of the previous layer, and determine the proportion of the layer relative to a certain criterion, that is, sort the influence of $n$ factors on a certain target in the upper layer. The comparison above is between two factors. In order to quantify the importance of each element in the matrix, a matrix judgment scale (1 - 9 scale method) is introduced (Table 1). Use $a_{i j}$ to represent the comparison of the $i$-th factor with respect to the $j$-th factor, then:

$$
\begin{gathered}
a_{i j}=\frac{1}{a_{j i}} \\
A=\left(a_{i j}\right)_{n \times n}=\left(\begin{array}{cccc}
a_{11} & a_{12} & \cdots & a_{1 n} \\
a_{21} & a_{22} & \cdots & a_{2 n} \\
\vdots & \vdots & \ddots & \vdots \\
a_{n 1} & a_{n 2} & \cdots & a_{n n}
\end{array}\right)
\end{gathered}
$$


Table 1. Proportional scale of relative importance of two elements.

\begin{tabular}{cc}
\hline Proportional scale & Meaning \\
\hline 9 & The former is extremely important. \\
7 & The former is much more important. \\
3 & The former is more important. \\
1 & The former is slightly more important. \\
$1 / 3$ & The former is as important as the latter. \\
$1 / 5$ & The latter is slightly more important. \\
$1 / 7$ & The latter is more important. \\
$1 / 9$ & The latter is extremely important. \\
$8,6,4,2$, & Intermediate value of the above evaluation value \\
$1 / 2,1 / 4,1 / 6,1 / 8$ &
\end{tabular}

$A$ is called a pairwise comparison matrix.

\subsection{Study Area Description}

Putian, the prefecture-level city of Fujian Province, the famous hometown of overseas Chinese, the hometown of Mazu, who is the goddess of peace in the Straits, is also the Mazu cultural center of the world [7]. Putian is one of the economic zones on the west coast of the Taiwan Strait. It is located in the central part of Fujian's coastal area, bordered by Fuzhou in the north and Quanzhou in the south and facing Taiwan across the Strait. It also owns National 4A tourist resorts like Weizhou Island, South Shaolin, Jiuli Lake, Jiulong Valley, etc, places endowed with the fine spirits and beautiful scenery of the universe [8]. According to the statistical bulletin of the National Economic and Social Development of Putian City in 2016, Putian received 311,400 inbound tourists, an increase of $15.4 \%$ over the previous year; the number of domestic tourists received was $23,157,700$, an increase of $18.8 \%$; domestic tourism revenue was 18.601 billion yuan, an increase of $28.6 \%$, and total tourism revenue was 20.297 billion yuan, an increase of $28.1 \%$ [9].

\subsection{Data}

This paper uses the basic climate data of Putian City from 1988 to 2017, meteorological data from three artificial observation stations in Putian, Xianyou and Xiuyu from 1988 to 2017 and negative oxygen ion data for three scenic spots in Weizhou Island, Jiuyi Lake and Jiulong Valley from 2014 to 2017.

\subsection{Construction of Comfort Index Model}

\subsubsection{Selection of Common Comfort Index Model}

Putian is located in the southeast coast and has a subtropical maritime monsoon 
climate. Therefore, it is affected by meteorological factors such as high temperature, high humidity and strong wind. In this paper, the model for evaluating the comfort index should first include the Temperature and Humidity Index, the Wind Cold Index, and the Index of Cloth Loading. The specific calculation formula is as follows.

Temperature and Humidity Index is referred to as THI [4].

$$
\mathrm{THI}=(1.8 t+32)-0.55(1-f)(1.8 t-26)
$$

where $t$ is Celsius $\left({ }^{\circ} \mathrm{C}\right)$ and $f$ is relative humidity (\%).

Wind Cold Index is referred to as WCI [5].

$$
\mathrm{WCI}=(33-t)(9+10.9 \sqrt{V}-V)
$$

where $t$ is Celsius $\left({ }^{\circ} \mathrm{C}\right)$ and $V$ is average wind speed $(\mathrm{m} / \mathrm{s})$.

Index of Cloth Loading is referred to as ICL. In order to more fully express the weight of each meteorological element in the comfort index, this article adds the ICL. In addition to the basic meteorological data Celsius temperature $\left({ }^{\circ} \mathrm{C}\right)$ and average wind speed, the calculation process also involves the human metabolic rate, the absorption of solar radiation by the human body, the calculation of the solar constant and the solar elevation angle, providing a strong reference significance. Calculated as follows [6]:

$$
\mathrm{ICL}=\frac{33-t}{0.155 H}-\frac{H+a R \cos \alpha}{(0.62+19 \sqrt{V}) H}
$$

where $t$ is Celsius $\left({ }^{\circ} \mathrm{C}\right), V$ is average wind speed $(\mathrm{m} / \mathrm{s}), H$ indicates the metabolic rate (usually $75 \%$ ) in the case of a slight amount of exercise in the human body, taking $87 \mathrm{~W} / \mathrm{m}^{2}$, and $a$ indicates the absorption of solar radiation by the human body (the maximum value of 0.06 in the case of black clothing is taken). For the convenience of calculation, the solar constant is taken as the value measured by the artificial satellite of $1366 \mathrm{~W} / \mathrm{m}^{2}$, and the solar elevation angle is calculated according to the seasonal variation.

\subsubsection{Selection of New Air Comfort Index}

With the improvement of the air quality requirements of the tourist destination and the promotion of the concept of "Fresh Fujian", this paper adds the air quality index and negative oxygen ion concentration as the innovation point in the climate comfort model, which is more able to characterize tourists' demands and desire for fresh air. In 2014, three major scenic spots in Weizhou Island, Jiuyi Lake and Jiulong Valley established negative oxygen ion monitoring stations. This paper calculates the Air Comfort Index (ACI) of the city's tourist attractions by the average of the monitoring data provided by each scenic spot. According to the data published by relevant departments in China, the classification of air negative oxygen ion concentration is as follows (Table 2) [10].

In order to further calculate the air anion concentration evaluation index and integrate it into the comprehensive climate comfort evaluation model, the negative 
Table 2. Negative oxygen ions corresponding to ACI.

\begin{tabular}{ccc}
\hline Negative oxygen ion concentration (pieces $\left./ \mathrm{cm}^{3}\right)$ & Level & Air freshness \\
\hline 2000 & 1 & Very fresh \\
$1500-2000$ & 2 & Fresh \\
$1000-1500$ & 3 & Relatively fresh \\
$500-1000$ & 4 & Generally fresh \\
$<500$ & 5 & Not fresh \\
\hline
\end{tabular}

Data source: Indicators commonly used by research scholars.

oxygen ion concentration should be converted. The most widely used evaluation indicators are the unipolar coefficient and the air quality evaluation coefficient, which is hereinafter referred to as the ACI. The unipolar coefficient $q=n^{+} / n^{-}$, where $n^{+}$is the air positive ion concentration and $n-$ is the air negative ion concentration. In the lower atmosphere, the $q$ value is generally less than 1.2 , and the $q$ value can be as low as 0.53 in the high mountains.

$$
\mathrm{ACI}=n^{-} / 1000 q
$$

According to the geographical and climatic characteristics of Putian, $q$ takes 1.2 , and 1000 is the air negative oxygen ion concentration that meets the minimum requirements of human biological effects. When ACI $>1.0$, it is level A, amd the air is very fresh. ACI is B level between 1.0 and 0.7 , the air is fresh. ACI is $C$ level between 0.69 and 0.50 , the air is relatively fresh. And ACI is $0.49-0.30$, the level is $\mathrm{D}$, which is general. ACI $\leq 0.29$ is not fresh.

For more accurate and convenient analysis of various indexes, this paper cites references for grading and assigning THI, WCI, ICL and ACI. The specific classification and assignment are shown below (Table 3).

\subsubsection{Construction of Comprehensive Tourism Climate Comfort Model} In summary, the tourism climate comfort index model of Putian City selects the Temperature and Humidity Index THI, the Wind Cold Index WCI, the Index of Cloth Loading ICL and the Air Comfort Index ACI. Then the new comprehensive tourism climate comfort index (CCI) is as follows.

$$
\mathrm{CCI}=a X_{\mathrm{THI}}+b X_{\mathrm{WCI}}+c X_{\mathrm{ICL}}+d X_{\mathrm{ACI}}
$$

\subsubsection{Determination of Indicator Weights of Comprehensive Climate Comfort Model}

The judgment matrix of this paper is divided into two levels. The first layer A represents $\mathrm{CCI}$, and the second layer B1, B2, B3, and B4 are THI, WCI, ICL and $\mathrm{ACI}$, respectively. According to the expert judgment method, the effect of the second layer factor B on the first layer factor A is as follows (Table 4).

According to Table 1, the row and normalization method can be used to obtain the weight assignment ranking vector $W=\left(\begin{array}{llll}0.45 & 0.29 & 0.17 & 0.09\end{array}\right)$ of all the indicators in the climate comfort evaluation hierarchical model, and then construct a new comprehensive climate comfort index model CCI, which is: 
Table 3. Specific classification and assignment of THI, WCI, ICL and ACI.

\begin{tabular}{|c|c|c|c|c|c|c|c|c|}
\hline THI & & WCI & & ICL & & ACI & & \\
\hline Range & Range & Human body feeling & Range & Clothing & Range & Air freshness & & \\
\hline$<40$ & $>1000$ & $\begin{array}{l}\text { Extremely cold and } \\
\text { extremely uncomfortable }\end{array}$ & $>2.5$ & $\begin{array}{c}\text { Thick sweater } \\
\text { plus down jacket }\end{array}$ & $<0.29$ & Not fresh & $\mathrm{E}$ & 1 \\
\hline $40-45$ & $1000-800$ & Cold and uncomfortable & $1.8-2.5$ & $\begin{array}{l}\text { Thick sweater } \\
\text { and cotton coat }\end{array}$ & $0.49-0.3$ & General & $\mathrm{D}$ & 3 \\
\hline $45-55$ & $800-600$ & $\begin{array}{l}\text { Relatively cold and } \\
\text { uncomfortable }\end{array}$ & $1.5-1.8$ & Sweater plus coat & $0.69-0.5$ & Relatively fresh & $\mathrm{C}$ & 5 \\
\hline $55-60$ & $600-300$ & Cool and comfortable & $1.3-1.5$ & Sweater plus thin coat & $1.0-0.7$ & Fresh & B & 7 \\
\hline $60-65$ & $300-200$ & Cool and very comfortable & $0.7-1.3$ & Shirts and casual clothes & $>1.0$ & Very fresh & A & 9 \\
\hline $65-70$ & $200-50$ & Warm and comfortable & $0.5-0.7$ & Long sleeve shirts & $1.0-0.7$ & Fresh & B & 7 \\
\hline $70-75$ & $50-0$ & Hot and uncomfortable & $0.3-0.5$ & Short sleeve shirts & $0.69-0.5$ & Relatively fresh & $\mathrm{C}$ & 5 \\
\hline $75-80$ & $0--50$ & Stuffy and uncomfortable & $0.1-0.3$ & $\begin{array}{l}\text { Short-sleeved } \\
\text { summer dress }\end{array}$ & $0.49-0.3$ & General & $\mathrm{D}$ & 3 \\
\hline$>80$ & $<-50$ & $\begin{array}{l}\text { Extremely stuffy and } \\
\text { extremely uncomfortable }\end{array}$ & $>2.5$ & T-shirts and shorts & $<0.29$ & Not fresh & $\mathrm{E}$ & 1 \\
\hline
\end{tabular}

Table 4. Comparison matrix.

\begin{tabular}{ccccc}
\hline $\mathrm{A}$ & $\mathrm{B}_{1}$ & $\mathrm{~B}_{2}$ & $\mathrm{~B}_{3}$ & $\mathrm{~B}_{4}$ \\
\hline $\mathrm{B}_{1}$ & 1 & 2 & 3 & 4 \\
$\mathrm{~B}_{2}$ & $1 / 2$ & 1 & 2 & 3 \\
$\mathrm{~B}_{3}$ & $1 / 3$ & $1 / 2$ & 1 & 2 \\
$\mathrm{~B}_{4}$ & $1 / 4$ & $1 / 3$ & $1 / 2$ & 1 \\
\hline
\end{tabular}

Data source: Based on expert judgment of the importance of each factor.

$$
\mathrm{CCI}=0.45 X_{\mathrm{THI}}+0.29 X_{\mathrm{WCI}}+0.17 X_{\mathrm{ICL}}+0.09 X_{\mathrm{ACI}}
$$

Among them, $X_{\mathrm{THI}}, X_{\mathrm{WCI}}, X_{\mathrm{ICL}}$ and $X_{\mathrm{ACI}}$ represent the Temperature and Humidity Index, Wind Cold Index, Index of Cloth Loading and Air Comfort Index, respectively, and $0.45,0.29,0.17$, and 0.09 are the weight coefficients of each index. Because it is a simple single-layer indicator model, the matrix is completely consistent. According to the model, the comfort standard is as follows: when $6<\mathrm{CCI} \leq 9$, it is comfortable; when $5<\mathrm{CCI} \leq 6$, it is relatively comfortable; when $3<\mathrm{CCI} \leq 5$, it is relatively uncomfortable; when $1 \leq \mathrm{CCI} \leq 3$, it is uncomfortable.

\section{Evaluation Results of Climate Comfort in Putian City}

\subsection{Climate Comfort Index of Putian}

Results from the analysis of climate information is indicated in Table 5.

In terms of CCI, Putian is located on the coast, with high forest coverage and high negative oxygen ion concentration. According to the negative oxygen ion monitoring equipment arranged in the three tourist attractions of Jiuyi Lake, 
Table 5. Annual average data of three artificial observatories in Putian.

\begin{tabular}{|c|c|c|c|c|c|c|c|c|c|c|c|c|}
\hline & Jan & Feb & Mar & Apr & May & Jun & Jul & Aug & Sep & Oct & Nov & Dec \\
\hline 2 minutes average wind speed $(\mathrm{m} / \mathrm{s})$ & 2.17 & 2.4 & 1.93 & 2 & 2.07 & 2 & 2.33 & 2.37 & 2.23 & 2.9 & 2.27 & 2.53 \\
\hline Average temperature $\left({ }^{\circ} \mathrm{C}\right)$ & 14.67 & 12.77 & 14.83 & 20.53 & 24.3 & 26.17 & 29.73 & 29.8 & 28.9 & 24.67 & 19.87 & 14.77 \\
\hline Relative humidity (\%) & 74.33 & 72.33 & 78.67 & 74.67 & 78 & 89 & 74 & 76.67 & 73.67 & 64 & 70.67 & 60 \\
\hline Number of negative oxygen ions (pieces $/ \mathrm{cm}^{3}$ ) & 1168 & 1134 & 1468 & 1569 & 1677 & 1892 & 2104 & 2219 & 2175 & 2051 & 1742 & 1195 \\
\hline
\end{tabular}

Data source: Statistics of the Putian Municipal Meteorological Bureau from 1988 to 2017.

Jiulong Valley and Weizhou Island, the data from 2014 to 2017 are counted. According to the analysis, the annual average CCI of Putian is 1.41. Except that it has not reached 1 (relatively fresh) in January, February and December, other months has reached the fresh standard, and the overall appearance is inverted V-shaped (Figure 1).

\subsection{Evaluation Results of Climate Comfort in Putian}

Substitute the data in Table 5 into the model to calculate the specific data of the climate comfort index for each month, as summarized below (Table 6).

From the above table, we can get the evaluation results of tourism climate comfort in Putian City.

1) THI indicates that due to the high humidity, there is no most comfortable month in Putian, and the weather is hot and humid from June to September, and the evaluation result is stuffy, of which from July to September is extremely stuffy. The evaluation results are good from March to April and from November to January of the following year, all of which are level B. The temperature in February is low, and the evaluation result is cold and relatively uncomfortable. Weather in May and October is hot, relatively uncomfortable.

2) WCI indicates that due to geographical location and climatic conditions, WCI is not much different throughout the year, and it's overall comfortable. The most comfortable months are April and October. It is cool from November to March; and it is warm and comfortable from May to September.

3) ICL indicates that the most comfortable months in Putian are April and November, suitable for wearing casual clcothes such as shirts. It is stuffy from June to September, especially in July and August, which are level D, and the body feels much more stuffy, suitable for wearing short-sleeved shirts. It is cold in January and February, suitable for sweaters and jackets. It is comfortable in May and October, suitable for wearing light summer clothes. And in March and December, it would be better to dress casual clothes.

4) ACI indicates that except for December to February, air in Putian is relatively fresh, it is all fresh in the rest months. The reason may be that Putian is located on the coast, and the forest vegetation coverage is high.

5) In the comprehensive climate comfort evaluation, according to the calculation results of the final model, it can be seen that CCI in March, April and 
Table 6. Climate comfort in Putian city.

\begin{tabular}{ccccccccccccc}
\hline & Jan & Feb & Mar & Apr & May & Jun & Jul & Aug & Sep & Oct & Nov & Dec \\
\hline Average temperature $\left({ }^{\circ} \mathrm{C}\right)$ & 14.67 & 12.77 & 14.83 & 20.53 & 24.3 & 26.17 & 29.73 & 29.8 & 28.9 & 24.67 & 19.87 & 14.77 \\
Relative humidity (\%) & 74.33 & 72.33 & 78.67 & 74.67 & 78 & 92 & 89 & 76.67 & 73.67 & 64 & 70.67 & 60 \\
Average wind speed (m/s) & 2.17 & 2.4 & 1.93 & 2 & 2.07 & 2 & 2.33 & 2.37 & 2.23 & 2.9 & 2.27 & 2.53 \\
THI & 58.35 & 54.9 & 58.61 & 67.43 & 73.59 & 78.18 & 83.85 & 82.09 & 80.25 & 72.76 & 66.19 & 58.46 \\
THI level & B & C & D & B & C & D & E & E & E & C & B & B \\
WCI & 418.9 & 475.3 & 403.76 & 278.94 & 196.85 & 152.78 & 76.34 & 74.93 & 94.35 & 205.17 & 304.47 & 433.89 \\
WCI level & B & B & B & A & B & B & B & B & B & A & B & B \\
ICL & 1.6 & 1.74 & 1.36 & 1.1 & 0.65 & 0.44 & 0.28 & 0.26 & 0.43 & 0.67 & 1.05 & 1.62 \\
ICL level & C & C & B & A & B & C & D & D & C & B & A & B \\
ACI & 1.97 & 0.95 & 1.23 & 1.31 & 1.4 & 1.58 & 1.75 & 1.85 & 1.81 & 1.71 & 1.45 & 0.96 \\
ACI level & B & B & A & A & A & A & A & A & A & A & A & B \\
Climate comfort & BBCB & CBCB & BBBA & BAAA & CBBA & DBCA & EBDA & EBDA & EBCA & CABA & BbAA & BBBB \\
CCI & 6.66 & 5.76 & 7.18 & 8.1 & 6.28 & 5.04 & 3.35 & 3.35 & 3.69 & 6.86 & 7.52 & 7 \\
\hline
\end{tabular}

Data source: calculated from the above Equations (1)-(8).

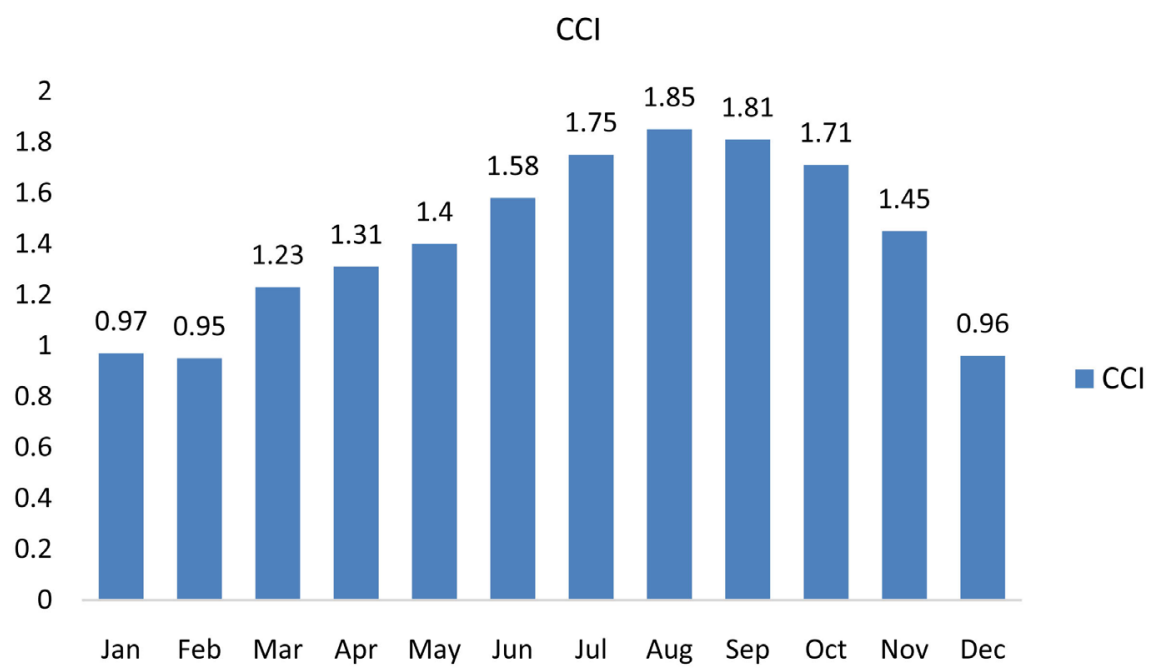

Figure 1. Trend of CCI. Data source: Substitute the data in Table 5. Into Equation (6).

November are between $0-1$, which is comfortable, hence these months are the most suitable for outdoor tourism activities in Putian. CCI in October, December and May are relatively comfortable and relatively suitable for tourism. In July and August, due to the excessive precipitation, the typhoon intrusion at any time, and the high temperature and humidity, the evaluation result is greater than 2, which is relatively uncomfortable, and it is not recommended to travel outside. In the remaining months, CCI are between $1-2$, which is relatively comfortable and can be arranged to travel outside. 


\section{Correlation Analysis of Climate Comfort and Passenger Flow in Putian City}

This paper uses the OLS regression method to determine whether there is a correlation between the monthly exponential of passenger flow and climate comfort, and characterize what kind of tourism the city is. Take climate comfort as an explanatory variable, and a regression equation is established with the tourist volume index to reveal the elastic coefficient and marginal effect of the climate comfort index in the monthly passenger index [11]. Through sorting, we select the total number of visitors received by Putian City from 2011 to 2017, and get the monthly index of the tourists and the monthly index of comfort (Table 7).

The chart is drawn by comparing the monthly tourists index and monthly comfort index (Figure 2).

From the figure, we can see that the monthly tourists index and the monthly comfort index are basically the same, showing an irregular $M$ shape, which belongs to the spring-autumn tourist city. In addition to poor comfort in Summer, it is good in other three seasons. We use climate comfort as an explanatory variable to establish a regression equation with the tourist volume index. The elastic coefficient and marginal effect of the climate comfort index in the monthly passenger index can be known. Now use the data above as the basis for calculation, use the OLS least squares method for regression analysis, and the simulation equation can be obtained as follows.

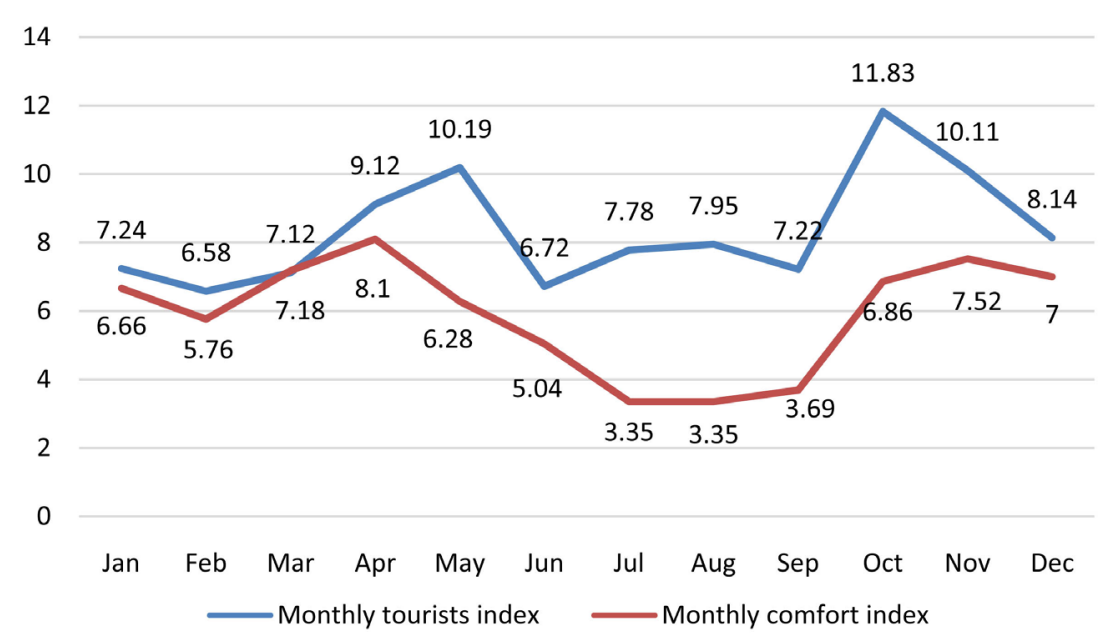

Figure 2. The monthly tourists index and monthly comfort index curve of Putian. Data source: Calculated by the model.

Table 7. Comparison of the monthly tourists index and monthly comfort index of Putian (Ten thousand people, \%).

\begin{tabular}{ccccccccccccc}
\hline & Jan & Feb & Mar & Apr & May & Jun & Jul & Aug & Sep & Oct & Nov & Dec \\
\hline Monthly average visitor volume & 105.3 & 95.6 & 103.5 & 132.6 & 148.2 & 97.7 & 113.1 & 115.6 & 104.9 & 172.1 & 146.8 & 118.4 \\
Monthly tourists index & 7.24 & 6.58 & 7.12 & 9.12 & 10.19 & 6.72 & 7.78 & 7.95 & 7.22 & 11.83 & 10.11 & 8.14 \\
Monthly comfort index & 6.66 & 5.76 & 7.18 & 8.1 & 6.28 & 5.04 & 3.35 & 3.35 & 3.69 & 6.86 & 7.52 & 7 \\
\hline
\end{tabular}

Data source: Putian City Tourism Bureau 2011-2017 statistics. 


$$
Q_{i}=3.6772+0.7893 \mathrm{CCI}
$$

where $Q_{i}$ represents the monthly tourists index, CCI represents the comfort level, that is, for every unit of climate comfort change, the monthly passenger flow index will increase or decrease by $0.7893 \%$. The correlation coefficient $r$ is 0.8957 and $\mathrm{p}$ is 0.0048 , and the equation is significantly correlated, indicating that changes in climate comfort will result in changes in passenger flow.

\section{Analysis of Tourism Development in Putian City}

This paper uses the scientific method to fit the weather comfort and the monthly change of tourists in Putian City. According to the data, the fit between the comfort index and the passenger flow is good, and there are slight differences in individual months. Despite the hot summers, the climate comfort index of $\mathrm{Pu}$ tian City is high in other seasons, which is suitable for traveling. However, in fact, CCI in winter is high but the number of tourists is small, implying that it is urgent to promote tourism in the seasons with less tourists but better comfort. This paper specifically proposes the following suggestions.

1) CCI of Putian City in November and December are 7.2 and 7, respectively, which means comfortable, but the number of tourists drops significantly from November to December. The reason may be that there is often strong wind in coastal areas in early winter, and the island tourism comfort is not high. Therefore, it is recommended to promote tourism promotion in inland mountainous areas during this period. The data shows that the wind speed of Xianyou and Putian is smaller than that of the coastal Xiuyu observation point, while the scenic spot in the inland is not affected by the strong wind. Scenic spots such as Jiuyi Lake and Jiulong Valley can launch special packages in the off-season from November to increase the attractiveness of tourists, and carry out multimedia promotion methods to increase the off-season publicity and increase the number of tourists.

2) Although the island tourism is affected by the winter winds, festivals like the "Kite Festival" can be held in the off-season according to the overall climate predictions and upcoming weather forecasts of the meteorological department to attract tourists, and carry out some indoor folk culture exhibitions and other relaxed travel itineraries.

3) The data shows that it is hot from June to September and not suitable for traveling, and there are fewer festivals to worship Mazu in summer. However, as an emerging island tourist city, summer activities such as island swimming and camping can be promoted in Putian to attract young tourists.

4) It is recommended that the relevant departments of Putian continue to increase investment in transportation. In the winter, the closed-end tourist vehicles in scenic spots should be added, while in the summer, open-type sightseeing vehicles can be used, and the consumption of scenic spots is supposed to be clearly priced, so that tourists can have a better experience. 


\section{Conclusions}

The following conclusions were drawn from this study.

1) In this paper, the AHP method is used to derive the tourism climate comfort index model of Putian City, and the OLS analytic method is used to fit the climate comfort with the monthly change of passenger flow, the result of which is good, proving that there is a clear correlation between the comfort index and the passenger flow, and the analysis in this paper can be considered to be of practical significance.

2) The number of tourists in Putian City is increasing year by year and has obvious time distribution characteristics. There are two peak periods in which tourists are concentrated in each year, which are April to May and October to November, belonging to the spring-autumn type. The climate of Putian is a typical subtropical maritime monsoon climate, which is greatly affected by typhoon and rain in summer. Besides, the temperature and humidity are high in summer, hence the amount of tourists does not show the peak even in summer vacation. In October, the climate is comfortable and pleasant, with less precipitation and lower humidity, and due to the National Day Golden Week, there are more passengers in the month. In April and May, due to the moderate temperature and humidity and the higher climate comfort, and there are festivals celebrating the birthday of Mazu, the number of tourists is higher. In the above four months with more tourists, the number of tourists is particularly high in October, while it is significantly less from June to September, and typhoons and hot weather are direct factors.

3) According to the model, although there is a slight difference between the climate comfort index and the tourists' index in individual months, there is no particularly cold season in Putian, which indicates that Putian has good meteorological conditions, a comfortable period of the whole year, and has strong conditions for promoting tourism.

4) The innovation of this paper lies in the fact that when constructing the comfort evaluation model, it not only uses the conventional Temperature and Humidity Index, the Wind Cold Index, the Index of Cloth Loading, but also adds the Air Comfort Index that tourists now pay special attention to, so it has practical significance and reference value. However, the negative oxygen ion monitoring station in Putian was newly built in 2014, so only the average value of 4 years was taken. In the future research, it is necessary to continue collecting relevant materials and perfect the theoretical research basis.

\section{Recommendations}

According to the calculation and analysis, comparing the climate comfort index and the tourists index, this paper puts forward some suggestions with practical significance to the relevant scenic spots and departments. For example, using multimedia publicity, preferential ticket purchases and other means to strengthen the tourism promotion in the early winter season, promote inland moun- 
tain tourism in the winter, strengthen the summer holiday tourism promotion of island students in the summer, continue to do a good job in the scenic area supporting transportation, catering and other services.

\section{Conflicts of Interest}

The authors declare no conflicts of interest regarding the publication of this paper.

\section{References}

[1] Tang, D.C., Wang, L.J. and Li, C.S. (2014) Research on Xiamen Tourism Climate Comfort Evaluation Based on FAHP Model. Journal of Fujian Normal University (Natural Science Edition), 5, 101-108.

[2] Tang, D.C., Wang, L.J., Li, C.S. and Li, M.M. (2014) Fuzzy Comprehensive Evaluation of the Impacts of Climate Change on Tourism in Xiamen. Progressus Inquisitiones de Mutatione Climatis, 5, 370-376.

[3] Tang, D.C., Tang, J.X. and Ma, T.Y. (2016) Environmental Regulation Efficiency and TFP in China-Econometric Explanation Based on SBM-Undesirable and DEAMalmquist. Journal of Arid Land Resources and Environment, 11, 7-12.

[4] Liu, Q.C., Wang, Z. and Xu, S.Y. (2007) Climate Suitability Index for City Tourism in China. Resources Science, 1, 133-141.

[5] Ma, L.J., Sun, G.N., Li, L.F. and Wang, M. (2008) Correlative Analysis of Climate Comfort and Monthly Variation of Tourists in Haikou City. Resources Science, 11, 1754-1759.

[6] Zhu, L.Y., Qian, P.D. and Qian, Y. (2001) Weather Index Study for Clothing. Scientia Meteorologica Sinica, 4, 468-473.

[7] Chen, S.Y. (2000) Research on Personalization and Scale of Putian Tourism Development. Fujian Geography, 1, 43-46.

[8] Chen, B.M., Chen, X.L. and Deng, D.H. (2010) Research on the Construction of Tourism Image in Putian City. Journal of Hubei University of Economics, 8, 48-50.

[9] Putian City Statistics Bureau (2016) Statistical Communique of 2016 National Economic and Social Development of Putian City.

[10] Chinese Research Academy of Environmental Sciences, China National Environmental Monitoring Center (2018) Ambient Air Quality Standards.

[11] Cao, W.H., He, Y.Q., Li, Z.S., Wang, S.X., Wang, C.F. and Chang, L. (2012) Correlation Analysis of Lijiang Tourism Climate Comfort and Passenger Flow Changes during the Year. Scientia Geographica Sinica, 12, 1489-1464. 


\section{Abbreviation Note List}

\begin{tabular}{cc}
\hline Abbreviation & Meaning \\
\hline AHP & Analytic Hierarchy Process \\
OLS & Ordinary Least Square \\
THI & Temperature and Humidity Index \\
WCI & Wind Cold Index \\
ICL & Index of Cloth Loading \\
ACI & Air Comfort Index \\
CCI & Climate Comfort Index \\
$t$ & Celsius $\left({ }^{\circ} \mathrm{C}\right)$ \\
$f$ & Relative humidity $(\%)$ \\
$V$ & Average wind speed (m/s) \\
$H$ & Metabolic rate \\
$a$ & Absorption of solar radiation by the human body
\end{tabular}

